\title{
Usability of Polymer Concrete as a Machine-Making Material Regarding Fatigue Strength
}

\section{Ergun Ateş, Mahmut Nedim Gerger}

Department of Mechanical Engineering, Faculty of Engineering and Architecture, Balıkesir University, Balıkesir, Turkey. Email: ergunates@balikesir.edu.tr, ngerger@balikesir.edu.tr

Received September $24^{\text {th }}, 2013$; revised October $18^{\text {th }}, 2013$; accepted October $25^{\text {th }}, 2013$

Copyright (C) 2013 Ergun Ateş, Mahmut Nedim Gerger. This is an open access article distributed under the Creative Commons Attribution License, which permits unrestricted use, distribution, and reproduction in any medium, provided the original work is properly cited.

\begin{abstract}
In many studies conducted on polymer concretes of different structures, some of the mechanical behaviours such as compression, bending, damping, and fatigue have been investigated. Specimens and experimental taxonomy used in the majority of these studies explore the idea of using polymer concrete either as a construction material or as a material for building the body of machine tools. The experimental methodology and specimens used in this study to investigate the fatigue strength were chosen according to the machine-making material. In "rotational flexural fatigue" experiments conducted using high compressive strength composite materials, fatigue strength values were observed to be lower than previous studies.
\end{abstract}

Keywords: Fatigue; Composite; Epoxy; Polymer Matrix

\section{Introduction}

Polymer concrete (PC) is a composite material that is obtained by mixing a filler material such as sand, marble, quartz, pearlite, glass, fibre, dolomite, steel, or carbon fibres with a resin such as unsaturated polyester, polymethylmethacrylate, or epoxy, and by adding a catalyst or accelerant at room temperature that allows toughening through polymerization. As a different type of cement concrete, polymer concrete is used in the construction industry as a material of construction in cover materials, water channels, spillways, prefabricated construction material, and also in the machine industry as a material for machine tool bodies, gearboxes, and pump bodies. Many disadvantages over metallic materials (especially cast iron), such as high dampening capacity, lightness, resistance to corrosion and chemicals, and relative ease of manufacturing made it a favourable manufacturing material and attracted the attention of many researchers.

Krause, J. et al.: They determined in their studies that if gearbox bodies were made of polymer concrete, vibrations would decrease [1]. Schulz, H.: In his study, he determined that the ultimate fatigue strength would be 5 $\mathrm{N} / \mathrm{mm}^{2}$ when he examined fatigue characteristics using filler material of quartz with a particle size of $0-8 \mathrm{~mm}$ and $7 \%$ epoxy for resin as weight ratio [2]. Nicklau,
R.G.: His study investigated the modulus of elasticity and compressive strength change rate as well as damping, elongation, and flexure fatigue strength values of polymer concrete with methacrylate resin. He calculated the continuous tensile strength of methacrylate resin polymer concrete under vibration strain as $5 \mathrm{~N} / \mathrm{mm}^{2}$ [3]. Dey, $\mathrm{H}$. J.: In his experiments, he studied the fracture and shape change of polymer concrete using three different resins and discovered that polymer concrete made with epoxy resin had the best vales [4]. Sahm, D.: In his study, the creep phenomenon and other mechanical properties of polymer concrete as body construction material were investigated and maximum values for compressive, tensile, and flexural strength were obtained using $10 \%$ epoxy resin, which had 8-mm particle size, by weight [5]. Rebeiz, K. et al.: They investigated elastic behaviour and other mechanical properties of polymer concrete and polymer mortars, and determined that using PET in polymer concrete helps to resolve solidification problems [6]. Gupta, K. et al.: In this paper, the use of nitinol [shape memory alloy (SMA)] wires in the fibre reinforced composite shaft (made of fibre glass and epoxy resin), for the purpose of modifying shaft stiffness properties to avoid such failures, is discussed. The comparison of the experimental results with the established ana- 
lytical results indicates feasibility of vibration control using the special properties of SMA wires [7]. Cheng T.H. et al.: The paper describes a structural stability analysis of fibre reinforced $10 \mathrm{~kW}$ composite laminate (made of the E-glass/epoxy orthotropic) wind turbine blades by using finite element method. The modal properties of the wind blade were investigated, including the natural frequency, mode sharps, and the centrifugal effect. The results of the nonlinear analysis of displacement and stress show much lower than the linear analysis, because of the geometry nonlinear effect [8]. Burks, B. et al.: The fatigue properties of a unidirectional carbon/glass/epoxy hybrid composite used as the load bearing member of the next generation high voltage transmission lines were evaluated. It was found that the composite showed a strong sensitivity to the amount of transverse loading when tested using the rotating beam method. It was also found that the composite exhibited a period of "wear-in" behaviour in which the composites' axial modulus increased substantially. This increase was attributed to a change in the alignment of the reinforcing fibres under the influence of an applied load [9]. Hedia, H.S. et al.: The aim of this research is to investigate experimentally the effect of nanocomposite coating on the fatigue life of carbon steel AISI 1045 specimens with different surface finishes. Fatigue tests are conducted on the respective specimens by a rotating bending machine of the cantilever type. Comparing the results for specimens coated with $0.5 \mathrm{wt} \%$ MWCNT-epoxy compositions with the base materials it is found that fatigue life increased five times for a roughness of $0.3 \mathrm{m \mu} / \mathrm{m}$ and three times for an average specimen roughness of $0.8,1.6$ and $2.5 \mathrm{~m} \mu / \mathrm{m}$, respectively [10].

In most of the theoretical and experimental studies mentioned above, the specimens and experimental methodology used in determining the mechanical properties of polymer concrete are usually based on the assumption of using polymer concrete in the construction and machine industries.

One of the most important phases of designing each and every element of a machine is selecting the best material. The best material is defined as the most suitable material that can best resist the physical and chemical conditions of the operation site. While metallic materials are still the primary choice for manufacturing machine parts, plastic and composite materials have an increasing rate of use as an alternative to the metallic materials. One advancement in this direction is the use of polymer concrete as an alternative to cast iron in manufacturing machine bodies. The characteristic values of different types of polymer concretes and cast iron are given in Table 1. Polymer concrete is suitable for this manufacturing process regarding many properties [4].

In most of the abovementioned studies, the properties
Table 1. Some characteristic values of polymer concrete and cast iron.

\begin{tabular}{ccc}
\hline Properties & Polymer concrete & Cast iron \\
\hline Elasticity Modulus, $\mathrm{kN} / \mathrm{mm}^{2}$ & $30-40$ & $80-130$ \\
Poisson rate & 0.2 & 0.3 \\
Compression strength, $\mathrm{N} / \mathrm{mm}^{2}$ & $100-160$ & $700-1200$ \\
Bend strength, $\mathrm{N} / \mathrm{mm}^{2}$ & $25-35$ & $300-600$ \\
Tensile strength, $\mathrm{N} / \mathrm{mm}^{2}$ & $12-18$ & $150-400$ \\
Damping & $6-8$ & 1 \\
Thermal elongation constant, $\mathrm{m} / \mathrm{mK}$ & $17 * 10^{-6}$ & $11 * 10^{-6}$ \\
Heat transmission coefficient, $\mathrm{kj} / \mathrm{mhK}$ & 6.8 & 210 \\
\hline
\end{tabular}

of polymer concrete regarding this aim were investigated or attempted to be improved. The essential properties are compressive, flexural, and damping strength values. These properties depend on resin, filler material type and its amount, as well as temperature, hardening time, and structural void ratio. Furthermore, machine elements are subjected to variable stresses in most companies. Metallic materials, which are strained under variable stresses, fail due to the widening of hairline cracks that are either pre-existing or formed within their elastic region. In this situation, known as fatigue, materials deform under their limit static strength. Even though systematic and theoretical approaches of experiments that are designed for metallic materials are sufficient to explain fatigue, they cannot provide accurate data in order to solve problems that emerge in design engineering.

The fatigue behaviour of non-metallic materials that are used as machine elements is far more complex. Heterogeneous structures may render the formation of a theoretical model and explaining the hairline crack formation virtually impossible. In obtaining the crack, dent, voids, particle size, phase distribution, fatigue strength of these materials, usage of the machine itself or its model instead of standard testing equipment, special tools, and simulating operation conditions may provide more reliable results. The fatigue strength of polymer concrete in the literature is obtained by experiments that consider the polymer concrete as a construction material. In this paper, polymer concrete composites with epoxy resin were tested by using the same fatigue equipment for metallic materials and an attempt was made to determine fatigue properties.

\section{Experimental Study}

It is known that polymer concrete can be formed by using many different mixtures and its properties vary depending on this mixture. Materials to be used are selected as follows, according to studies conducted in this area. 
Binder Choice: The literature review revealed that even though it has a price disadvantage, "epoxy resin" provides the best structural results in polymer concrete. In this study, epoxy resin was also used as the binder material. In short, epoxy resin is a thermoset composite, which has a liquid state at room temperature and hardens with the help of a hardening agent (polyaminoamide).

Filler Material: When polymer concrete studies are reviewed, it is seen that if epoxy resin is used in the mixture, quartz is recommended as the filler material. Quartz $\left(\mathrm{SiO}_{2}\right)$ was used in this study. Quartz is a very tough material, which has a specific mass of $2.5-2.9 \mathrm{~g} / \mathrm{cm}^{3}$ and is thermally stable up to $1610^{\circ} \mathrm{C}$ [11].

Filler Material Particle Size and Distribution: Particle size distribution of aggregates is determined using a method called granulemetry composition determination. Aggregates for filler material are classified according to their particle size conditions within the upper and lower limits for every particle size using standard size sieves. It is observed that particle sizes ranging from $16 \mathrm{~mm}$ to 2 $\mathrm{mm}$ were used for different polymer concrete applications. Therefore, the EN-12620 standard was taken as the basis for " $8 \mathrm{~mm}$ maximum aggregate particle size" [12]. Accordingly, \% - passing values for each standard sieve were determined for aggregates according to granulemetry curves that denote seven different composition groups (Table 2) [13,14].

Specimen Sizes: The determination of fatigue properties of polymer concrete as a comparison with metallic materials is only possible by using same-sized specimens. However, due to the particle sizes used and the structure to be formed, it is not possible to use small standard specimens as it is with metal specimens. In previous studies, $40 \times 40 \times 160 \mathrm{~mm}$ specimens and 4-point flexural strain experimental method was used as it is described in DIN51290-3 [15] and DIN-1045 [16], respectively. In the rotational flexural stress fatigue experiment, $40 \times 100$ $\mathrm{mm}$ specimens for $8 \mathrm{~mm}$ particle size were used as was recommended in ISO-4012 [17]. These sizes of speci-

Table 2. The percentage values of seven groups passing down the sieve by the purpose of using them in experimental study.

\begin{tabular}{cccccccc}
\hline \multirow{2}{*}{$\begin{array}{c}\text { Sieve numbers } \\
(\mathrm{mm})\end{array}$} & \multicolumn{7}{c}{ Groups } \\
\cline { 2 - 8 } & I & II & III & IV & V & VI & VII \\
\hline 8 & 100 & 100 & 100 & 100 & 100 & 100 & 100 \\
4 & 52 & 61 & 67.5 & 74 & 79.5 & 85 & 92 \\
2 & 28 & 36 & 46.5 & 54 & 64.5 & 72 & 79 \\
1 & 12 & 21 & 31.5 & 42 & 49.5 & 57 & 66 \\
0.5 & 5 & 12 & 19 & 26 & 32.5 & 39 & 46 \\
0.25 & 2 & 5 & 8 & 11 & 16 & 21 & 28 \\
\hline
\end{tabular}

mens stretch up to connection points, and specimens and cast specimens used with the point can be seen in Figure 1.

Binder and Filler Material Amounts: It is denoted that compressive and flexural strengths are high when $12 \%-17 \%$ binder material is used in a polymer concrete, where the binder material is epoxy resin and its hardener and the filler material is quartz (Figure 2) [18,19]. Compression tests for filler material's given particle sizes were made with three different binder ratios, i.e. $14.3 \%$, $18 \%$, and 22\%, and the distribution can be seen in Figure $3[13,14]$.

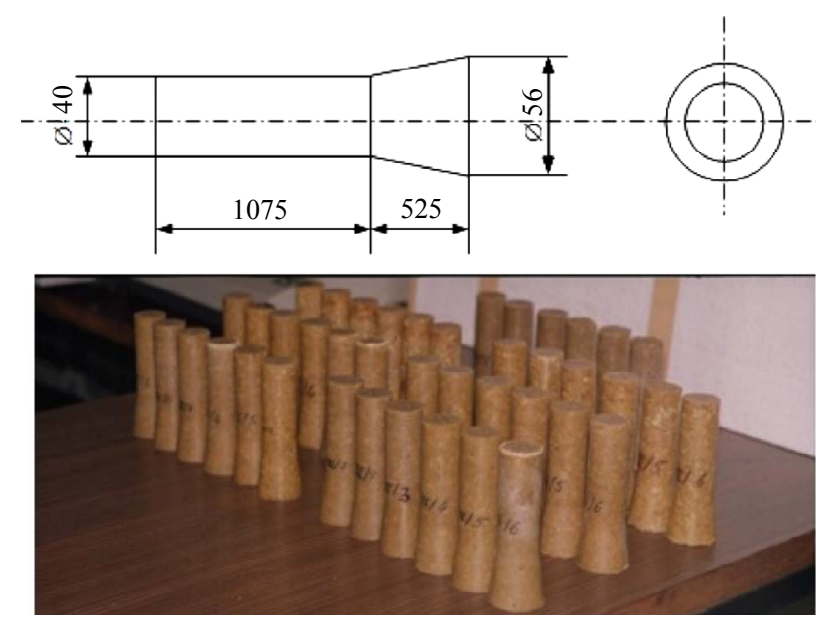

Figure 1. The samples of fatigue experiment.

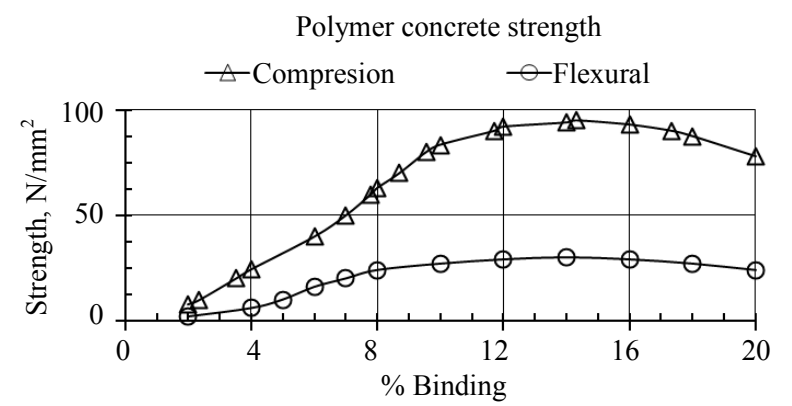

Figure 2. Polymer concrete compressive and flexural strength change.

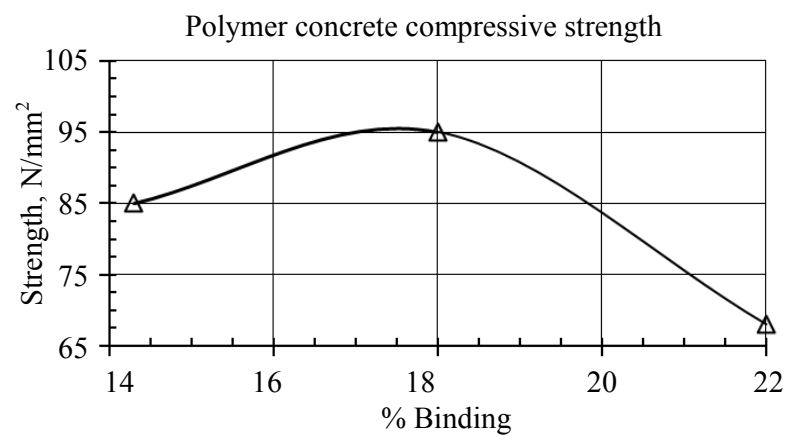

Figure 3. Polymer concrete compressive strength. 
Experimental Methodology: Stresses that are applied to the elements can vary in intensity and direction under normal operating conditions. The equipment used in the fatigue test was grouped according to the stresses that were applied. Since the aim was to determine the usability of polymer concrete as a machine-making material and its fatigue properties, a "rotating flexural stress fatigue testing machine", which is used for metallic materials, was used [20] (Table 3). The equipment manufactured for fatigue tests of epoxy resin-composite materials is given in Figure 4.

\section{Results and Discussion}

Considering the fact that fatigue tests are very long and extensive research is being conducted on the usability of polymer concrete as a machine tool body material, rather than testing all resin values, $18 \%$ resin specimens, of which compressive strength is the highest, were prepared

Table 3. The characteristics of bending, fatigue experiment device.

\begin{tabular}{|c|c|}
\hline Mark & Amsler bending, fatigue experiment device \\
\hline Type & BE 133 \\
\hline Dimensions & $600 \times 820 \times 1350 \mathrm{~cm}$ \\
\hline Net weight/Brut weight & $370 / 450 \mathrm{~kg}$ \\
\hline Maximum weight & $52 \mathrm{~kg}$ \\
\hline Number of cycles & $3000 / 2000 / 1000 \mathrm{rev} / \mathrm{min}$ \\
\hline Electric motor power & $1 / 2 \mathrm{PS}$ \\
\hline Cycle counter & $1 \mathrm{rpm} / 100 \mathrm{rpm}$ (work piece) \\
\hline Applications & $\begin{array}{l}\text { Normally, all of the standard metal samples } \\
\text { have been influenced by heat or corrosion }\end{array}$ \\
\hline Firm & $\begin{array}{l}\text { Alfred J. Amsler \& Co. } \\
\text { Schaffhausen/Schweiz }\end{array}$ \\
\hline
\end{tabular}

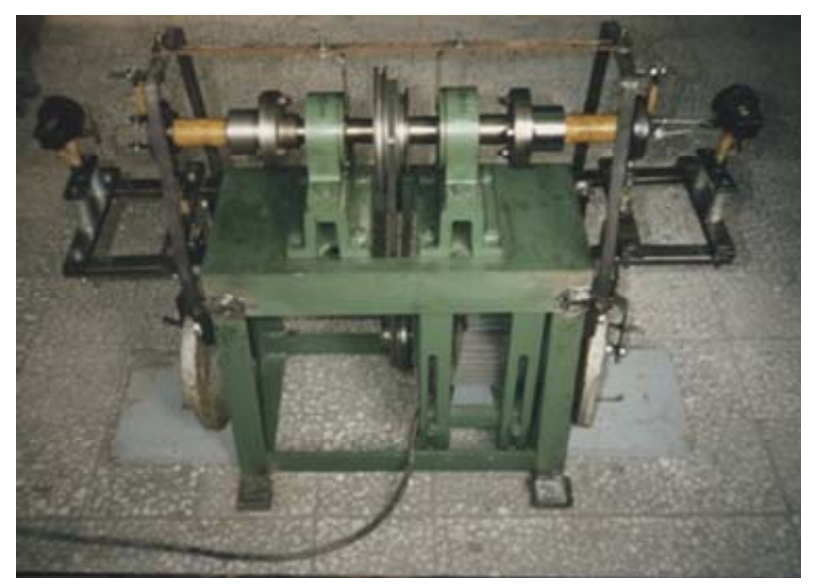

Figure 4. The bending, fatigue experiment device. as composite materials. An attempt was made to determine the fatigue strength of polymer concrete by using a unique experimental methodology, which was previously used for metallic materials. "Stress-load repetition values", where all groups are denoted, can be found in Figure 5. It was denoted that specified groups G4, G5 and especially G6 exceeded $10^{7}$ number of loadings even under a stress of $1.6 \mathrm{~N} / \mathrm{mm}^{2}$. Therefore, the order regarding fatigue strengths happens to be G6, G5, and G4.

According to the results, particle filler materials were not useful for fatigue strength. Different filler materials can be used to increase of the fatigue strength. There were many studies in literature about to used fibre materials for fatigue tests. Especially, fibre materials have been choosing. Particle quartz composites have been produced as a homogeneous inner structure distribution. But, this was not enough to a good rotational flexural fatigue strength. To be homogeneous of inner structure of particle quartz had been a very good result for compression strength. Also, flexural strength has remained quite low level too. The epoxy resin binder was not a problem here. The weak bonds between the particles of quartz was a main reason to low fatigue strength. Composite structure must be strong gravitational force between grains. Observed in the experimental studies, the elastic, solid and continuously filler element could be an ideal reinforced materials for fatigue strength of composite materials.

\section{Conclusions}

- When the obtained test results are compared with metallic materials, it is observed that polymer concrete has a much lower fatigue strength.

- Similar to other composite materials, when the stress level decreases, the loading cycle number before failure increases.

- It is not possible to mention a continuous strength range for epoxy resin and quartz filled composite materials. However, it can be said that the fatigue strength limit is between $1-1.6 \mathrm{~N} / \mathrm{mm}^{2}$, which corresponds to $10^{7}$ loading cycles.

- Since the fatigue strength of polymer concrete, which was prepared with epoxy resin and quartz filler material, is very low, it can be said that polymer concrete is not suitable for manufacturing machine elements, where a high fatigue strength is required.

- It is determined that mechanical and damping properties of polymer concrete are related to the amount of used binder and filler materials, particle size of filler material, and different particle size distributions.

- Since a homogeneous structure cannot be achieved in composite materials where a filler material is used, high deviations in the strength values are observed. Therefore, it can be said that the strength of polymer 


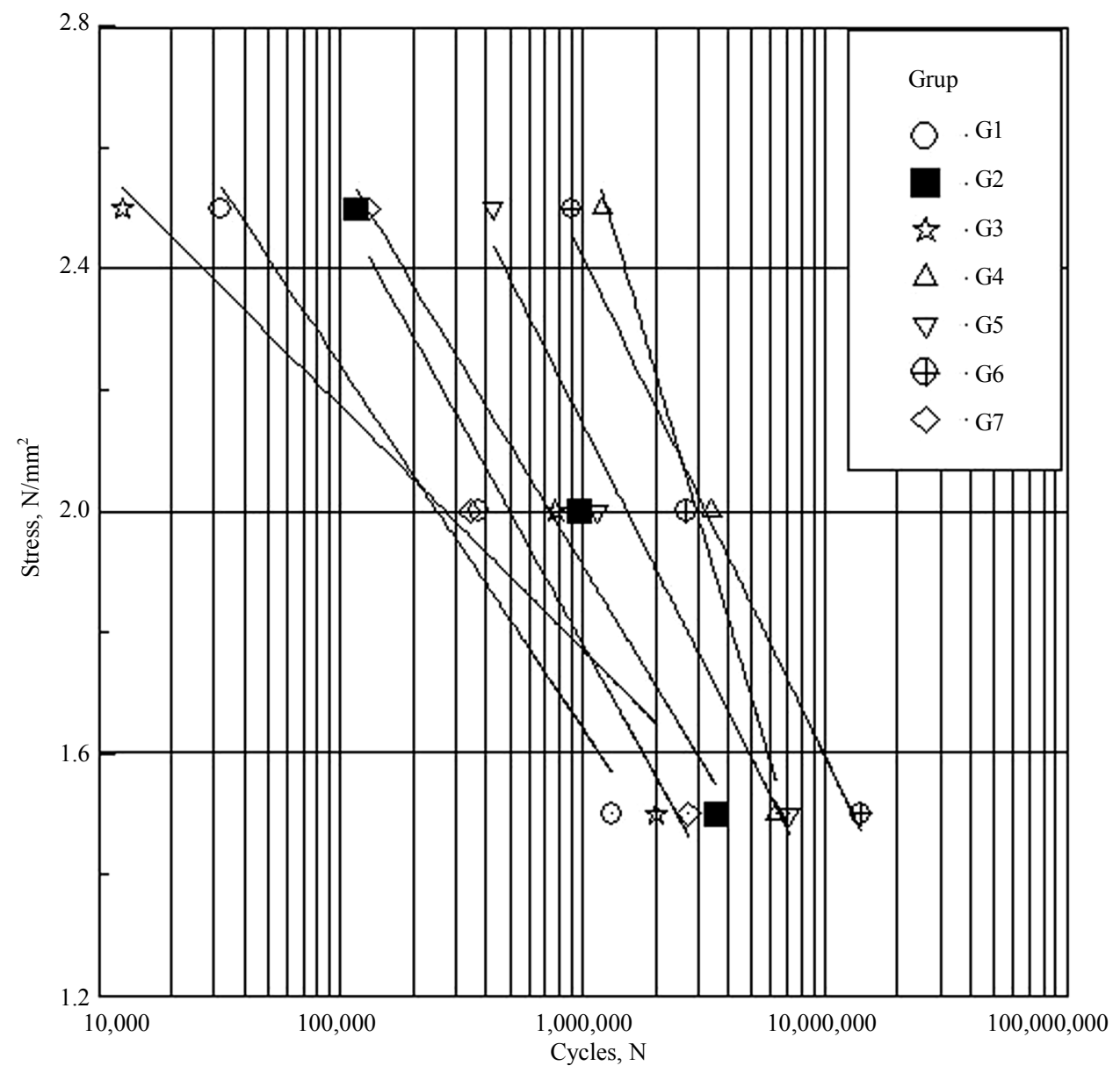

Figure 5. The results of fatigue tests for polymer concrete samples.

concrete depends on many parameters.

- Different structures that are obtained by using different resins and filler materials exhibit different properties.

- In order to obtain a suitable composite material, which can accommodate the conditions and requirements of the application field, it is imperative that the parameters on which the properties of the polymer concrete depend are thoroughly investigated and experimented within a broad scale.

\section{REFERENCES}

[1] J. Krausse and H. Dey, "Maschinenteile aus Polymerbeton," Sonderdruck aus Maschine, Werkzeug, Vol. 85, No. 13, 1984, pp. 16-23.

[2] H. Schulz, "Reaktionsharzbeton im Werkzeugmaschinenbau," Industrie Anzeiger, Vol. 14, No. 21, 1986, pp. 4142.

[3] R. G. Nicklau, "Werkzeugmaschinengestelle Aus Methacrylatharzbeton," Fortschr, Ber. VDI Reihe 2, Nr. 94, 1985, Düsseldorf.

[4] H. J. Dey, "Das Verformungs und Bruchverhalten von
Reaktionsharzbeton und die Auswirkungen auf Maschinenbauteile," Hanser, 1991.

[5] D. Sahm, "Reaktionsharzbeton Für Gestellbauteile Spanender Werkzeugmaschinen," Von der Fakültaet Für Maschinenwesen der Rheinisch-Westfalischen Technischen Hochschule, Aachen, 28 September 1987, pp. 1-130.

[6] K. S. Rebeiz, D. W. Fowler and D. R. Paul, "Time and Temperature Dependent Properties of Polymer Concrete Made with Resin Using Recycled PET," In Search of Excellence Annual Technical Conferance, Antec Conferance Proceedings, Pub. By Soc. Of Plastics Engineers, Brookfield, Vol. 37, 5 May 1991, pp. 2146-2149.

[7] K. Gupta, S. Sawhney, S. K. Jain and A. K. Darpe, "Stiffness Characteristics of Fibre-Reinforced Composite Shaft Embedded with Shape Memory Alloy Wires," Defence Science Journal, Vol. 53, No. 2, 2003, pp. 167-173.

[8] T. H. Cheng, I. S. Kim, S. Y. Park, Z. Z. Li and Y. D. Shen, "Title: Structural Stability Analyses of Composite Laminate Wind Turbine," Applications of Engineering Materials, PTS 1-4, Advanced Materials Research, Vol. 287-290, No. 7, 2011, pp. 1486-1491. http://dx.doi.org/10.4028/www.scientific.net/AMR.287-2 90.1486

[9] B. Burks, D. Armentrout and M. Kumosa, "Charaterization of the Fatigue Properties of a Hybrid Composite 
Utilized in High Voltage Electric Transmission," Composites: Part A, Vol. 42, No. 9, 2011, pp. 1138-1147. http://dx.doi.org/10.1016/j.compositesa.2011.04.019

[10] H. S. Hedia, S. M. Aldousari, A. Khairy and E. Aljabarti, "Fatigue Life Behaviour of Nanocomposite Coated Carbon Steel," Materials Testing, Vol. 54, No. 4, 2012, pp. 249-256.

[11] M. F. Ashby and D. R. H. Jones, "Engineering Materials 2. An Introduction to Microstructures, Processing and Design," Engineering Department, Cambridge University, England, Pergamon Press, Vol. 39. 1986, pp. 201-240.

[12] EN 12620, "European Standard. Aggregates for concrete".

[13] E. Ateş, "The Investigation of Use as a Machine Structural Material of Epoxy Polymer Concrete," Ph.D. Thesis, Balikesir University, Institute of Science and Technology, Balıkesir, 1994, p. 195.

[14] M. N. Gerger and E. Ateş, "Usability of the Polymer Concrete As Machine Manufacturing Material in terms of Fatigue Strength," Congress of 8th International Machine Design and Manufature, METU, Ankara, 9-11 September
1998, pp. 299-307.

[15] DIN 51290-3, "Testing of Polymer Concretes (Re-Action Resin Concretes) for Mechanical Engineering Purposes; Testing of Separately Manufactured Specimens," The German Institute for Standardization.

[16] DIN 1045, "Concrete, Reinforced and Pre Stressed Concrete strUctures," The German Institute for Standardization.

[17] ISO 4012, "Concrete-Determination of Compressive Strength of Test Specimens," International Organzation for Standardization.

[18] "Systems for Coatings and Building Protection, Surface Protection," Industrial Chemicals, Schering, 1994.

[19] "Industrial Chemicals, Surface Protection I-II, Systems for Coatings and Building Protection, Solvent Based Paints and Epoxy Emulsion Paints," Technical Information, Europox, Eurodur, Schering, 1994.

[20] “Amsler Bending, Fatigue Experiment Device," Al-fred J. Amsler \& Co. Schaffhausen, Schweiz. 